\title{
MEMBRANE INITIATED GELSOLIN AMYLOID FORMATION
}

\author{
Inta Liepina \\ Latvian Institute of Organic Synthesis, \\ Aizkraukles str. 21, \\ Riga, LV1006, \\ Latvia \\ e-mail: inta@osi.lv \\ Cezary Czaplewski \\ Faculty of Chemistry, University of Gdansk, \\ ul. Sobieskiego 18, \\ 80-952 Gdansk, \\ Poland \\ e-mail:czarek@chemik.chem.univ.gda.pl
}

\author{
Paul A. Janmey \\ Institute of Medicine and Engineering, \\ University of Pennsylvania, \\ Philadelphia, PA 19104, \\ USA \\ e-mail: janmey@mail.med.upenn.edu \\ Adam Liwo \\ Faculty of Chemistry, University of Gdansk, \\ ul. Sobieskiego 18, \\ 80-952 Gdansk, \\ Poland \\ e-mail: adam@chemik.chem.univ.gda.pl
}

\section{KEYWORDS}

Gelsolin, amyloid, amyloid formation, DMPC membrane, molecular dynamics.

\begin{abstract}
Molecular dynamics method is applied to simulate amyloid formation process.

Mutated gelsolin amyloidogenic fragments 173-243 (G173-243) and 173-202 (G173-202) cause Finnish familial amyloidosis disease (FAF). The mechanism of possible amyloid formation involving gelsolin G173202 fragments and dimyristoyl-phosphatidylcholine (DMPC) lipid was investigated by means of molecular dynamics (MD). G173-202 fragment adhered to the DMPC membrane in $100 \mathrm{ps}$, retaining $\beta$-sheet structure, suggesting that a lipid membrane could bind G173-202 fragments and serve as a germ for amyloidogenesis.

Afterwards one more amyloidogenic fragment G173202 was placed in the vicinity of G173-202 adhered to the DMPC membrane. After 700 ps of MD, the newly added amyloidogenic fragment G173-202 was interacting with the membrane attached fragment G173-202, indicating the possible mechanism of membrane initiated amyloidosis.
\end{abstract}

\section{INTRODUCTION}

Molecular dynamics method is useful computer calculations method to simulate interactions of molecules on a time scale thus simulating physiological and pathophysiological processes. In this work molecular dynamics is applied to simulate gelsolin amyloid formation process. Molecule interactions as the sum of all atom pair interactions (pair-wise approximation) are described in the same manner as in classic molecular mechanics of empirical force fields (Leach, 1996):

$E=E_{\text {bond }}+E_{\text {angle }}+E_{\text {tor }}+E_{e l}+E_{v d W}+E_{H-\text { bond }}$ (1), where $E_{\text {bond }}$ is the bond-stretching energy, $E_{\text {angle }}$ is the valence-angle-bending energy, $E_{\text {tor }}$ is the torsional energy (which arises because of intrinsic barriers to rotation about the bonds), $\mathrm{E}_{\mathrm{el}}$ is the electrostatic energy, $E_{v d W}$ is the energy of van der Waals interactions, and $E_{H \text {-bond }}$ comprises $E_{v d W}$ between the protons and electronegative atoms that can form hydrogen bonds with them (it is treated separately, because usually different atom-type-dependent parameters are required than those for non-hydrogen-bonding atom pairs). In the present work the flexible valence geometry force field AMBER was used:

$$
E_{\text {bond }}=\sum_{\text {bonds }} \frac{k_{d i}}{2}\left(d_{i}-d_{e i}\right)^{2}
$$

where $d_{i}$ is the actual length of the $i$ bond, $d_{e i}$ is the equilibrium length (the length of a non-strained bond), and $k_{d i}$ is the force constant.

$$
E_{\text {angle }}=\sum_{\substack{\text { bond } \\ \text { angles }}} \frac{k_{\theta i}}{2}\left(\theta_{i}-\theta_{e i}\right)^{2}
$$

where $\theta_{i}$ is the actual value of the ith valence angle, $\theta_{e i}$ is the equilibrium value, and $k_{\theta i}$ is the force constant. Electrostatic energy is described as a sum of the interaction of charges localized on atomic nuclei,

$$
E_{e l}=332 \sum_{\substack{i<j \\ i, j \text { nobonded } \\ \text { andot } \text {,3nonbonded }}} \frac{q_{i} \cdot q_{j}}{\varepsilon \cdot r_{i j}}
$$

The energy of van der Waals interactions is described by the Lennard-Jones potential, 


$$
E_{v d W}=\sum_{\substack{i<j \\ i, j \text { not bonded } \\ \text { and not 1,3-nonbobded } \\ \text { and not hydrogen-bonded }}} \frac{A_{i j}}{r_{i j}}-\frac{B_{i j}}{r_{i j}}
$$

where $A_{i j}$ and $B_{i j}$ are constants depending on the types of interacting atoms.

$$
E_{H-\text { bond }}=\sum_{\substack{\text { hydrogen -bonding } \\ \text { pairs }}} \frac{C_{i j}}{r_{i j}}-\frac{D_{i j}}{r_{i j}}
$$

The torsional energy, $E_{t o r}$, is expressed by

$$
\begin{aligned}
& E_{\text {tor }}=\sum_{\substack{\text { torsion } \\
\text { angles }}} \frac{V_{1 i}}{2}\left(1+\cos \varphi_{i}\right)+\frac{V_{2 i}}{2}\left(1-\cos 2 \varphi_{i}\right)+ \\
& +\frac{V_{3 i}}{2}\left(1-\cos 3 \varphi_{i}\right)
\end{aligned}
$$

In molecular dynamics, successive configurations of the system are generated by integrating Newton's equations. The result is a trajectory that specifies how the positions and velocities of the atoms in the system vary with the time. The trajectory is obtained by solving the Newton's equation: $(F=m a)$ for the particle with mass $m_{i}$ moving along the coordinate $\mathrm{x}_{\mathrm{i}}$ being driven by force $F_{x i}$ :

$$
\frac{d^{2} x_{i}}{d t^{2}}=\frac{F_{x i}}{m_{i}}
$$

similarly

$$
\begin{aligned}
& \frac{d^{2} y_{i}}{d t^{2}}=\frac{F_{y x i}}{m_{i}} \\
& \frac{d^{2} z_{i}}{d t^{2}}=\frac{F_{z i}}{m_{i}}
\end{aligned}
$$

where $x_{i}, y_{i}$ and $z_{i}$ are the Cartesian coordinates at $i$ th atom, $F_{x i}, F_{y i}, F_{z i}$ are the components of the forces acting on that atom and $m_{i}$ is the mass of $i$ th atom.

The forces are derivatives of energy $E$, described in (1).

$$
F_{x i}=\frac{\partial E}{\partial x_{i}}
$$

The molecule system described by above mentioned method consists of protein molecule fragments amyloidogenic fragments of gelsolin, and of a membrane bilayer fragment.

Gelsolin is a six-domain dynamic actin-filament binding, severing and capping protein capable of severing and nucleating of the actin cytoskeleton (Kwiatkowski, 1999). By modulating actin network via actin assembly and disassembly gelsolin regulates cell shape and motility (Kwiatkowski, 1999; Sun et al., 1999; Robinson et al., 1999; Laine et al., 1998) in the cytoplasm and cleans blood from stray actin filaments (Lee et al., 1992). In addition to actin regulatory function, gelsolin affects cell growth through the regulation of apoptosis (Sun et al., 1999). Cellular actin scaffold is continuously reorganized in response to a variety of signals. Apoptosis promotes dismantling the actin cytoskeleton, growth factor stimulation induces actin filament assembly at the plasma membrane, which changes cell shape and regulates cell movement. Gelsolin is a calcium-activated regulator of the actin cytoskeleton (Kwiatkowski, 1999; Robinson et al., 1999). Elevated calcium ion concentration activates actin filament severing and capping activities of gelsolin, which results in shorter actin filaments. Another type of gelsolin activation is performed by caspase-3, which cleaves the $\mathrm{Ca}^{2+}$-insensitive $\mathrm{N}$-half from the $\mathrm{Ca}^{2+}$-dependent $\mathrm{C}$-half (Kothakota et al., 1997). $\mathrm{Ca}^{2+}$ opens up gelsolin by inducing conformational changes in the C-half (Kwiatkowski et al., 1989; Patkowski et al., 1990), to expose actin binding sites of the N-half; thus the C-half acts as a regulatory domain to impose calcium regulation on the N-half. Caspase-3 acts cleaves the regulatory C-half, thus giving the N-half calcium uncontrolled actinsevering activity.

Human gelsolin is expressed as an $81 \mathrm{kDa}$ protein in the cytoplasm and an $84 \mathrm{kDa}$ protein in the plasma (Kwiatkowski et al., 1986a,b). The secreted protein differs by a signal sequence required for export and a 25-residue N-terminal extension. Human gelsolin has $87 \%$ sequence similarity to horse gelsolin (Koepf \& Burtnick, 1998; McLaughlin \& Gooch, 1992)).

Natural gelsolin exists in two forms - cytoplasmic and plasmic, which are derived from the same gene by alternative splicing (Kwiatkowski et al., 1986a,b). The cytoplasmic or intracellular gelsolin is a $84 \mathrm{kDa}$ protein responsible for the assembly of actin fragments during cytoskeletal formation and disassembly of actin filaments during cytoskeletal rearrangement. The cytoplasmic form of gelsolin modulates the actin cytoskeleton and plays a role in the cell motility and apoptosis (Kwiatkowski, 1999; Azuma et al., 1998; Kothakota et al., 1997). Plasma gelsolin is a scavenger that degrades stray actin filaments, thrown out from apoptotic cells into the blood plasma, and retrieves actin monomers for intracellular use. The cysteines at positions 188 and 201 (of human gelsolin) form a disulfide bond in the plasma gelsolin, whereas the cytoplasmic gelsolin form remains reduced (Wen et al., 1996). The actin severing function enables gelsolin to reduce the viscosity of blood and blood clots (Vasconcellos et al., 1994) or cystic fibrosis sputum (Davoodian et al., 1997).

Gelsolin folding occurs in the cytoplasm, where calcium ion concentration is normally low, and folding produces probably the inactive native protein, which can be activated by an increase in calcium concentration. Folding of gelsolin plasma form could take place in the endoplasmatic reticulum, where the free calcium ion concentration is 100-1000 M (Meldolesi \& Pozzan, 1998), which should be sufficient to generate the active, relaxed form (Zapun et al., 2000).

Plasma gelsolin is implicated in the familial amyloidosis-Finnish type (FAF), inherited disease. A point mutation in the $\mathrm{S} 2$ gelsolin domain causes an 
amyloidosis with neurological, ophthalmological and dermatological symptoms. This mutation does not affect the cytoplasmic form, while the plasma form is proteolysed, possibly both in the secretory pathway and in the extracellular medium (Kangas et al., 1996, 1999). Thus in addition to its role of actin binding, gelsolin domain S2 is involved in the pathogenesis of familial amyloidosis-Finnish type caused by inherited mutations D187N and D187Y in domain S2 of gelsolin (Maury et al., 1990). At the genetic level, FAF is caused by a single nucleotide substitution in the genomic DNA sequence of gelsolin where guanine 654 is replaced with adenine or thymine (De la Chapelle et al., 1992a,b). This causes replacement of an aspartate residue $\mathrm{Asp}^{187}$ with asparagine or tyrosine, which makes gelsolin susceptible to aberrant trypsin-like protease cleavage site between residues $\mathrm{Arg}^{172}-\mathrm{Ala}^{173}$ (Kangas et al., 1996). Structural changes unmask an aberrant proteolysis site at $\mathrm{Arg}^{172}$-Ala ${ }^{173}$ leading to a trypsin-protease sensitive molecule (Kiuru, 1998, Kiuru et al. 1999; Kiuru-Enari et al., 2002). The hydrolysis at the $\mathrm{Arg}^{172}-\mathrm{Ala}^{173}$ site results in the formation of a $68 \mathrm{kDa}$ C-terminal fragment, which is further digested at the $\mathrm{Met}^{243}$ residue, forming an amyloidogenic $8.1 \mathrm{kDa}$ peptide containing residues 173-243 (G173-243) of gelsolin domain S2 (Maury et al., 1997, 1994). The peptides G173-243 or its sequent cleavage fragment $\mathrm{Ala}^{173}-\mathrm{Gly}^{202}$, spontaneously associate into amyloid fibrils. The three-strand peptide Ala $^{173}$-Gly ${ }^{202}$ has a greater propensity to form amyloid fibrils then the amyloidogenic fragment G173-243 comprising four $\beta$-strands and an $\alpha$-helix (Weeds \& Maciver, 1993, Burtnick et al., 1997). The structure of the $\mathrm{Ala}^{173}-\mathrm{Gly}^{202}$ fragment consists of an antiparallel $\beta$ sheet that is stabilized by a disulphide bond, from $\mathrm{Cys}^{188}$ to $\mathrm{Cys}^{201}$ (Burtnick et al., 1997). Amyloid fibrils are deposited mainly in the facial regions, in the cornea and cranial nerve. As a result of deposition and accumulation of amyloid fibrils the FAF phenotype is characterized by corneal lattice dystrophy, cranial neuropathy, hyperelastic skin, facial muscle weakness, and renal complications (Kiuru, 1998). Mutated gelsolin has defective actin severing activity (Weeds \& Maciver, 1993), but FAF disease phenotype arises from the accumulation of extracellular amyloid tissues rather than the loss of gelsolin functions.

The mechanism of amyloidogenesis is not clear. In our previous work (Liepina et al., 2004) we started to investigate the mechanism of amyloid formation. In this work, using molecular dynamics (MD), we investigate interactions of gelsolin amyloidogenic fragments G173-202 [cleaved from the x-ray structure of gelsolin (1DON)] with dimyristoylphosphatidylcholine (DMPC) membrane bilayers.

\section{METHODS}

Method of molecular dynamics with AMBER force field was used.
Dimyristoylphosphatidylcholine (DMPC) lipid bilayer containing $6 \times 6$ arrays of DMPC molecules was taken from a previous study (Czaplewski et al, 1999). Mutated gelsolin amyloidogenic fragment 173-202 (G173-202) was cleaved from horse gelsolin crystal structure $1 \mathrm{DON}$.

The G173-202 fragment was placed $9 \AA$ away from a DMPC bilayer at two different starting orientations (Fig.1a) - start 1, and Fig. 2a) - start2) and subjected to NTP MD simulations at elevated body temperature $\mathrm{T}=312 \mathrm{~K}$ for $150 \mathrm{ps}$. After 100 ps of MD, the G173202 fragment at either initial orientation adhered to the DMPC membrane (Fig.1 b), Fig.2 b).

Afterwards one more amyloidogenic fragment G173202 was placed in the vicinity of the G173-202 fragment adhered to the DMPC membrane (Fig.3 a)), and the new system was subjected to NTP MD simulations at $\mathrm{T}=312 \mathrm{~K}$ for $3744 \mathrm{ps}$.

Subsequently all systems were placed in a periodic lipid-water box and subjected to MD simulations to investigate of the stability of the structures.

Preliminary calculations on DMPC lipid interactions with amyloid fragments G173-202 were carried out with program MOE, AMBER94 force field. Afterwards the peptide-lipid systems were surrounded by water layer forming periodic lipid-water box, and submitted to AMBER 7.0 molecular dynamics (MD) equilibration to investigate the stability of the systems. The pictures representing snapshots from molecular dynamics were created by program MOE.

\section{RESULTS AND DISCUSSION}

The gelsolin amyloidogenic fragment G173-202 was placed $9 \AA$ away from a DMPC bilayer at two different starting orientations (Fig.1 a) - start 1, and Fig. 2 a) start 2) and subjected to NTP MD simulations for 150 ps at the elevated body temperature $\mathrm{T}=312 \mathrm{~K}$, which is believed to promote amyloid structure formations. After 100 ps of MD simulations, the G173-202 fragment at either initial orientation adhered to the DMPC membrane (Fig. 1 b), Fig. 2 b), retaining $\beta$-sheet structure, suggesting that a lipid membrane could bind G173-202 fragments and serve as a germ for amyloidogenesis (Fig.1, Fig.2).

Afterwards one more amyloidogenic fragment G173202 was placed in the vicinity of G173-202 adhered to the DMPC membrane of the previous system "start-2" (Fig.3 a)), and the new system was subjected to NTP MD simulations at $\mathrm{T}=312 \mathrm{~K}$ for $3744 \mathrm{ps}$. After $700 \mathrm{ps}$ of $\mathrm{MD}$, the newly added amyloidogenic fragment G173-202 was interacting with the membrane attached fragment G173-202 and after 1465 ps they were bound with hydrogen bounds, indicating the possible mechanism of membrane initiated amyloidosis (Fig 3). Subsequently all systems were placed in a periodic lipid-water box and subjected to MD simulations to investigate of the stability of the structures. 


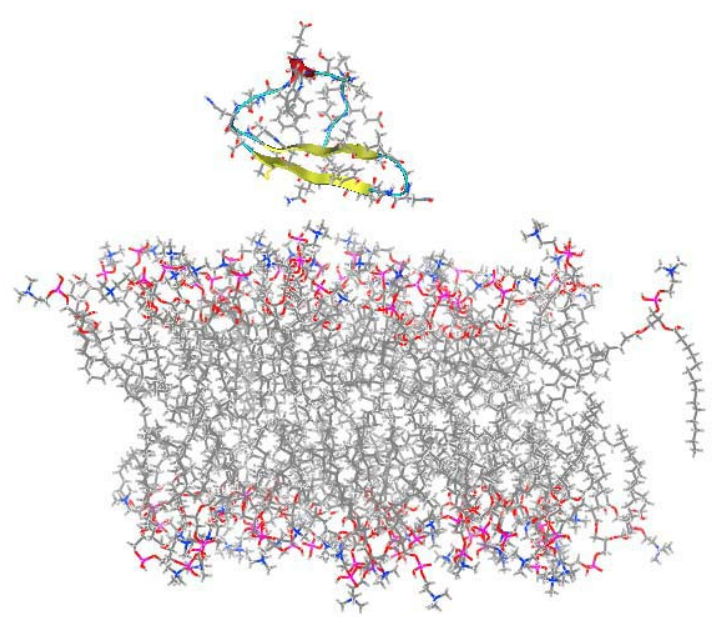

a) 0 ps

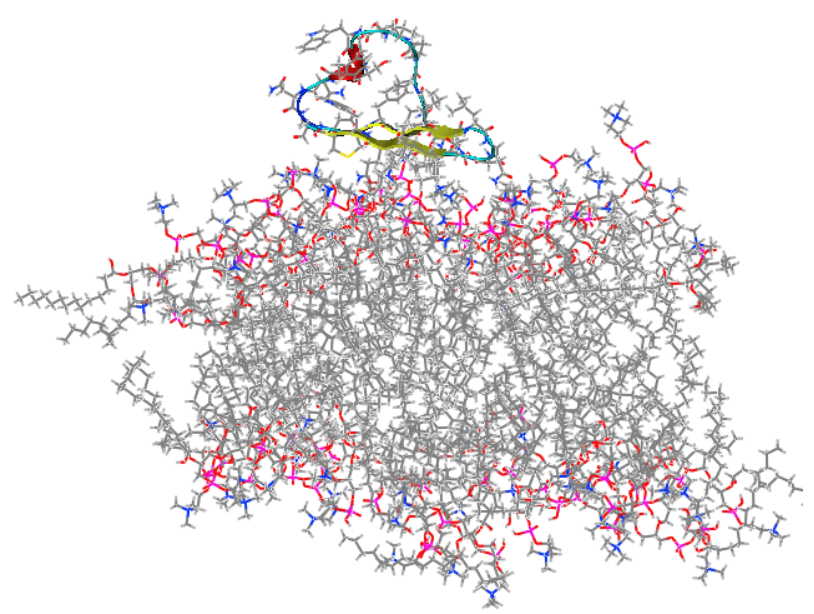

b) $99.5 \mathrm{ps}$

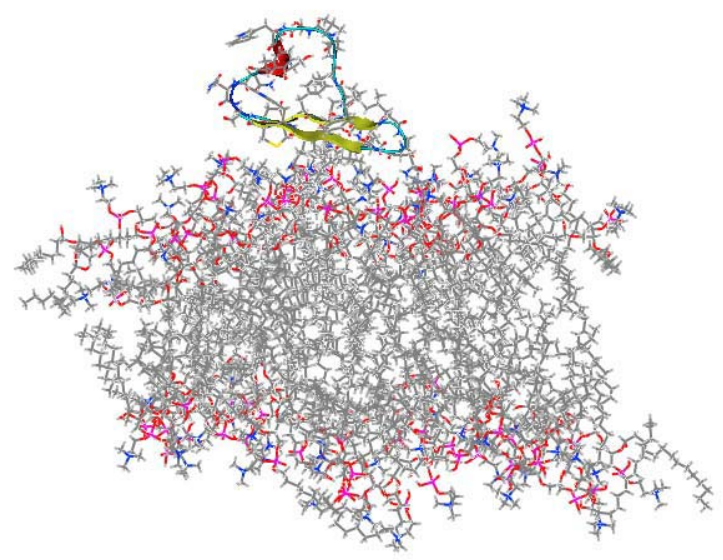

c) $144.5 \mathrm{ps}$

Fig.1. Molecular dynamics of the DMPC lipid with G173-202, start 1, at a) 0 ps, b) 99.5 ps, c) 144.5 ps.

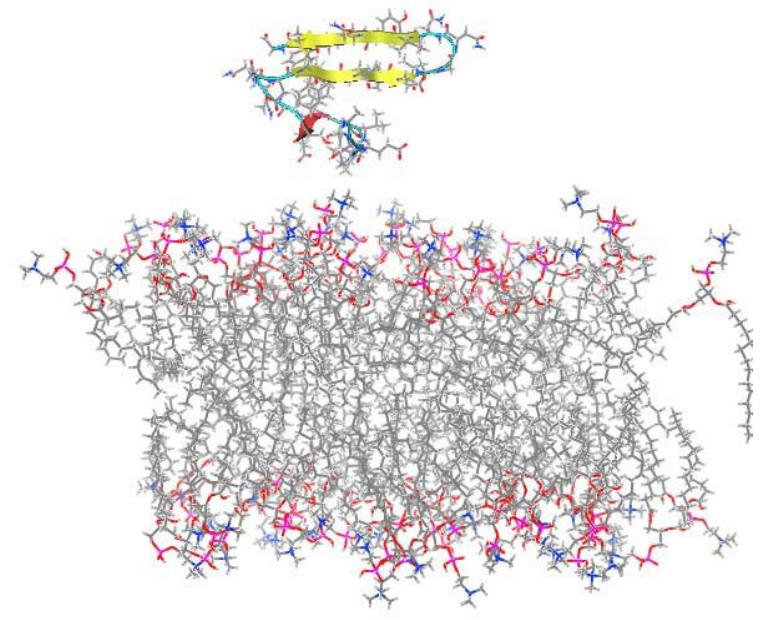

a) 0 ps

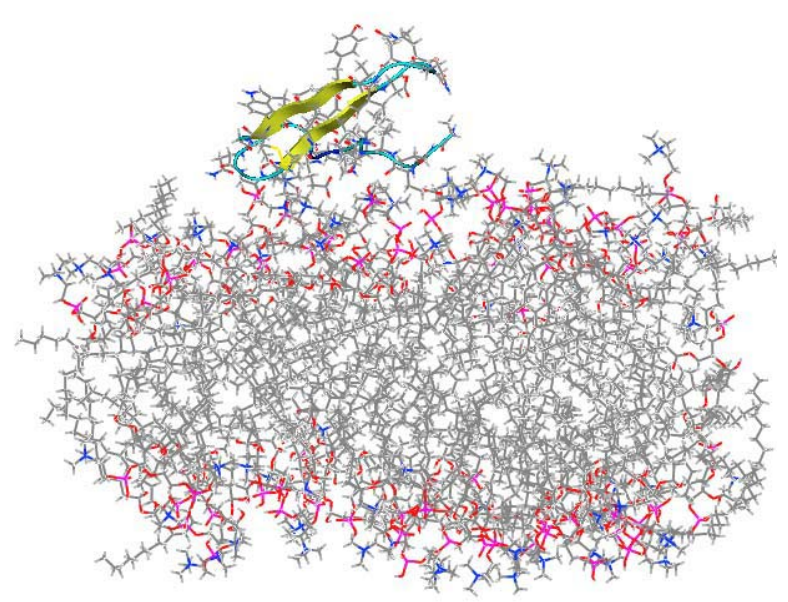

b) $100 \mathrm{ps}$

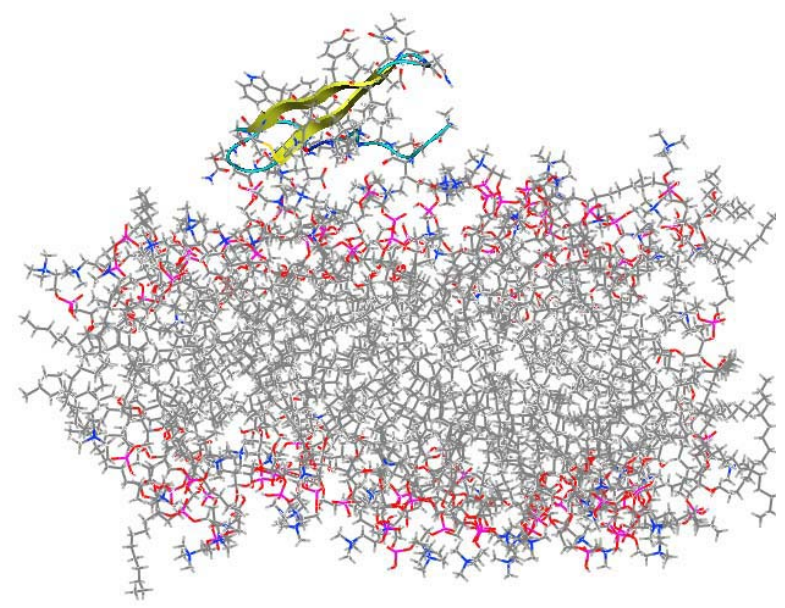

c) $149.5 \mathrm{ps}$

Fig.2. Molecular dynamics of the DMPC lipid with G173-202, start 2, at a) 0 ps, b) 100 ps, c) 149.5 ps. 


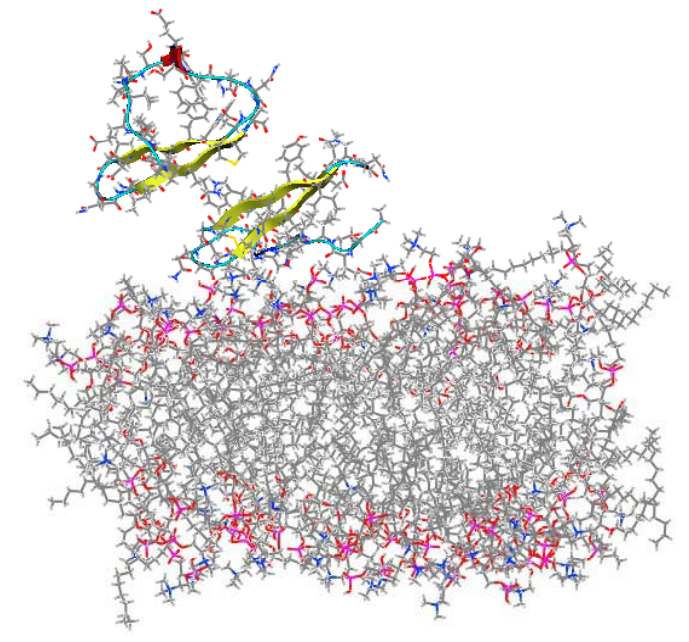

a) 0 ps

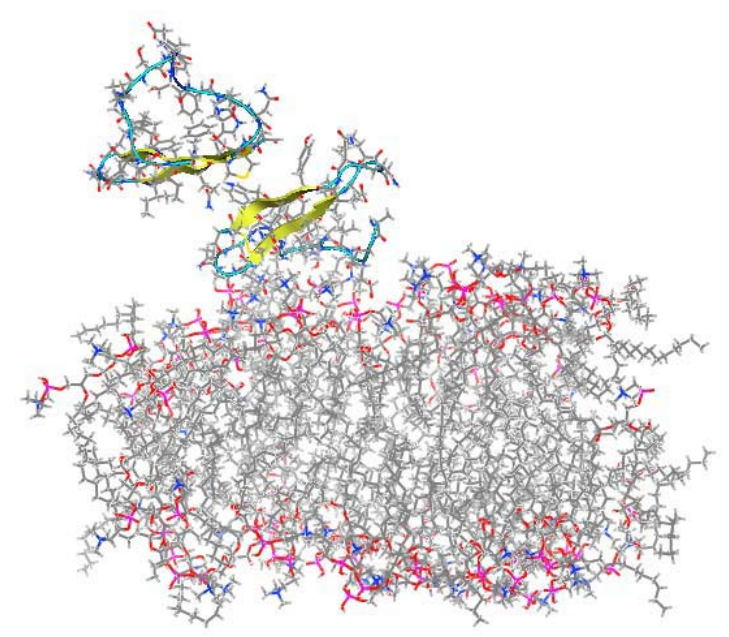

b) $50 \mathrm{ps}$

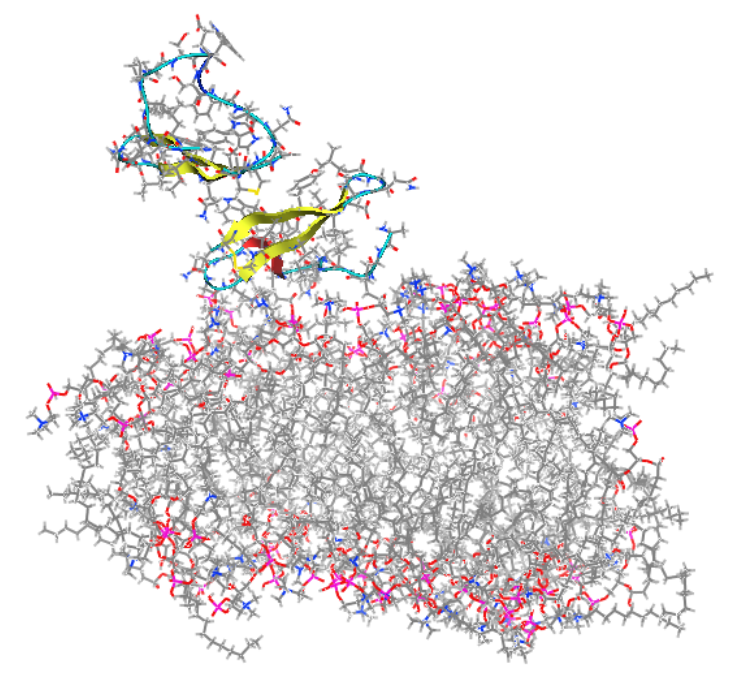

c) $129 \mathrm{ps}$

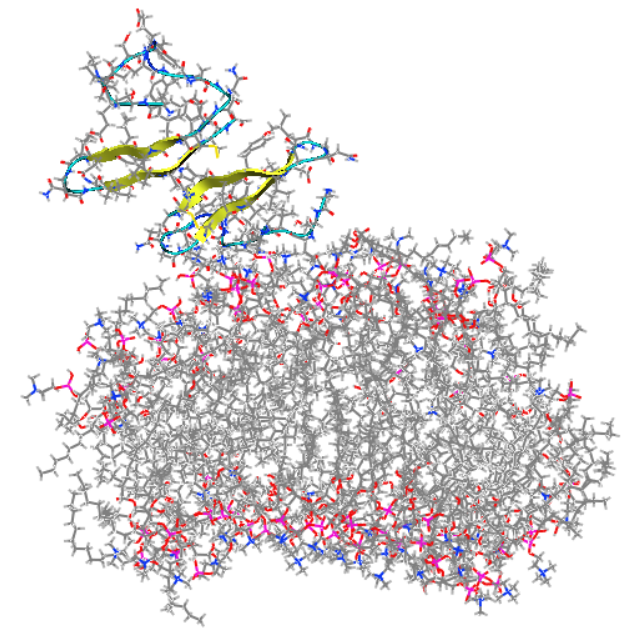

d) $789 \mathrm{ps}$

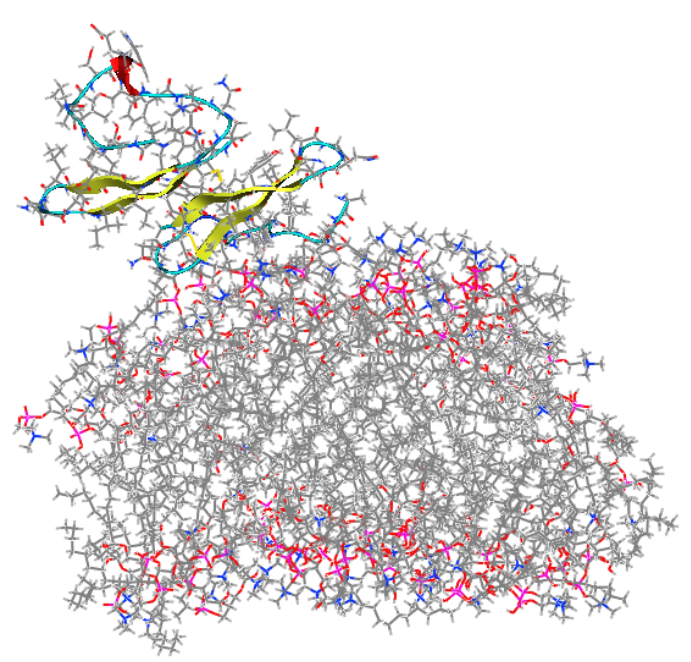

e) $1110.5 \mathrm{ps}$

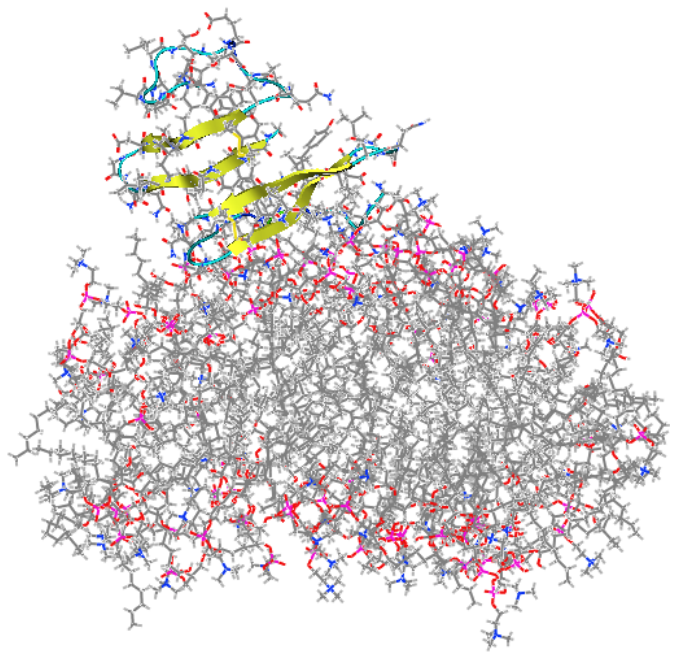

f) $1978 \mathrm{ps}$

Fig. 3. MD of DMPC lipid with two fragments of G173-202, at a) the start, 0 ps, b) 50 ps c) 129 ps, d) 789 ps, e) 1110.5 ps, f) $1978 \mathrm{ps}$ (to be continued). 


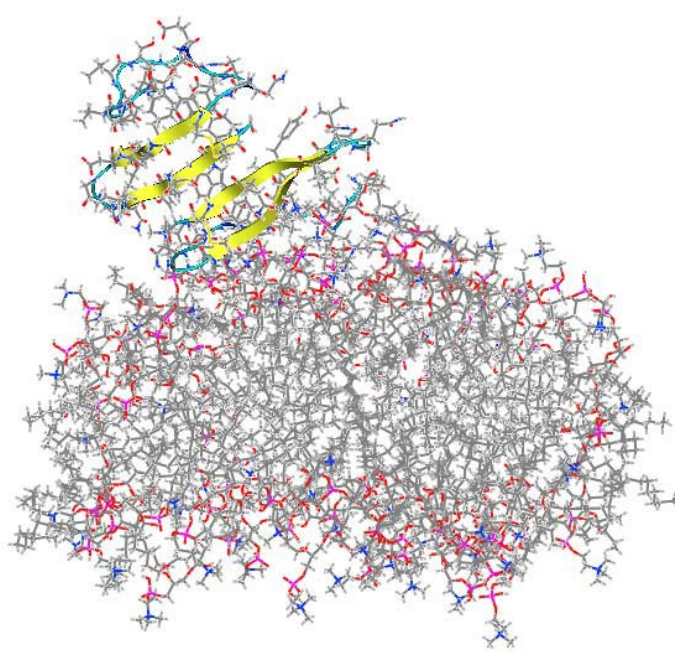

g) $2492 \mathrm{ps}$

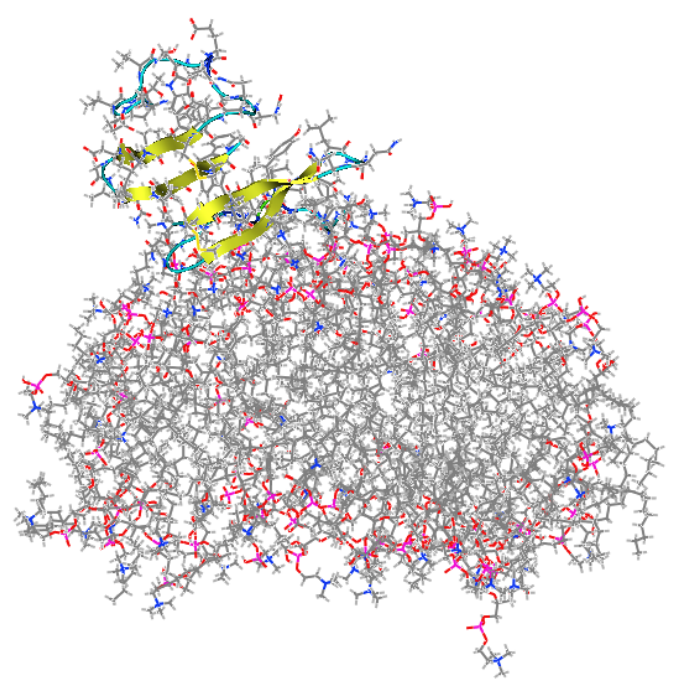

h) $3017 \mathrm{ps}$

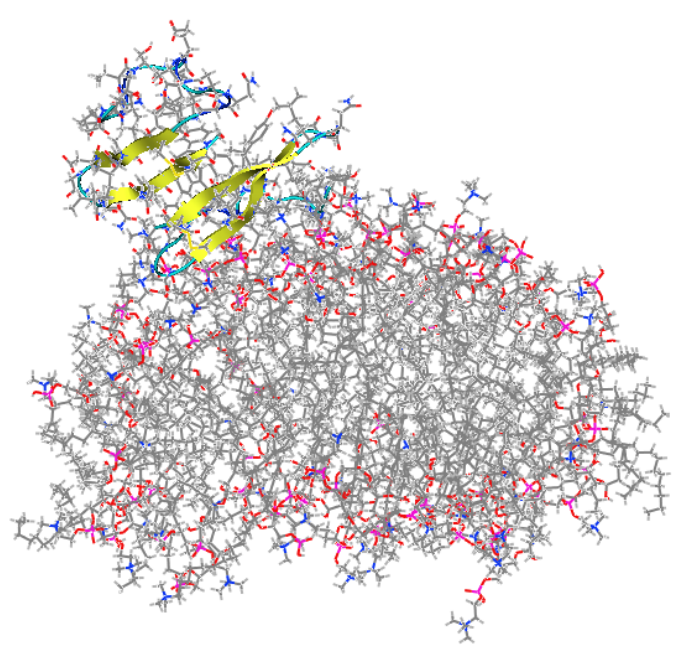

i) $3744 \mathrm{ps}$

Fig. 3. (continued) MD of DMPC lipid with two fragments of G173-202, at g) $2492 \mathrm{ps}$, h) $3017 \mathrm{ps}$, i) $3744 \mathrm{ps}$

\section{CONCLUSIONS}

Lipid membrane could bind G173-202 fragments and serve as a germ for amyloidogenesis.

Gelsolin fragments G173-202 could stick together forming $\beta$-structure.

Results show that such approach of molecular dynamics is reasonable to model the mechanism of amyloid formations.

\section{REFERENCES}

Azuma, T., Witke, W., Stossel, T. P., Hartwig, J. H. \& Kwiatkowski, D. J. Gelsolin is a downstream effector of rac for fibroblast motility. EMBO J., 17, 1362-1370, (1998).

Burtnick, L.D., Koepf, E.K., Grimes, J., Jones, E.Y., Stuart, D.I., McLaughlin, P.J., Robinson, R.C. The crystal structure of plasma gelsolin $\mathrm{V}$ implications for actin severing, capping and nucleation. Cell 90, 661-670, (1997).

Czaplewski, C., Pasenkiewicz-Gierula, M, Ciarkowski, J.. Molecular dynamics of a vasopressin V2 receptor in a phospholipid bilayer membrane. Journal of Receptor \& Signal Transduction Research, 19, 1999, 355-36

Davoodian K, Ritchings BW, Ramphal R, Bubb MR. Gelsolin activates DNase I in vitro and cystic fibrosis sputum. Biochemistry, 36(32), 96379641, (1997).

De la Chapelle A, Kere J, Sack GH Jr, Tolvanen R, Maury CP. Familial amyloidosis, Finnish type: G654 - a mutation of the gelsolin gene in Finnish families and an unrelated American family. Genomics, 13(3), 898-901, (1992a).

De la Chapelle, A, Tolvanen, R, Boysen, G., Santavy, J. Bleeker-Wagemakers, L, Maury, CP, Kere, J. Gelsolin-derived familial amyloidosis caused by asparagines or tyrosine substitution for aspartic acid residue 187. Nat. Genet., 2, 157-160, (1992b).

Kangas H, Paunio, T, Kalkkinen, N, Jalanko, A, Peltonene, L. In vitro expression analysis shows that the secretory form of gelsolin is the sole source of amyloid in gelsolin-related amyloidosis. Hum. Mol. Genet., 5, 1237-1243, (1996).

Kiuru-Enari S, Somer H, Seppalainen AM, Notkola IL, Haltia M. Neuromuscular pathology in hereditary gelsolin amyloidosis. J Neuropathol Exp Neurol., 61, 565-71, (2002).

Kiuru, S., Oili Salonen, Matti Haltia Gelsolin-related spinal and cerebral amyloid angiopathy Annals of Neurology, 45 (3), 305-311, (1999).

Kiuru, S. Gelsolin-related familial amyloidosis, Finnish type (FAF), and its variants found worldwide. Amyloid, 5 (1), 55-66, Review, (1998).

Koepf, E.K., J. Hewitt, H. Vo, R.T.A. Macgillivray and L.D. Burtnick. Equus caballus gelsolin.cDNA sequence and protein structural implications. 
European Journal of Biochemistry, 251, 613-621, (1998).

Kothakota, S., Azuma, T., Reinhard, C., Klippel, A., Tang, J., Chu, K., McGarry, T.J., Kirschner M.W., Koths, K., Kwiatkowki, D.J., Williams, L.T. Caspase-3-Generated Fragment of Gelsolin: Effector of Morphological Change in Apoptosis. Science, 278, 294-298, (1997).

Kwiatkowki, D.J. Function of gelsolin: motility, signaling, apoptosis, cancer. Current Opinion in Cell Biology, 11, 103-108, (1999).

Kwiatkowski DJ, Janmey PA, Yin HL. Identification of critical functional and regulatory domains in gelsolin. J Cell Biol., 108, 1717-1726, (1989).

Kwiatkowski D.J., Stossel T.P., Orkin S.H., Mole J.E., Colten H.R., Yin H.L. Plasma and cytoplasmic gelsolins are encoded by a single gene and contain a duplicated actin-binding domain. Nature, 323, 455-458, (1986).

Kwiatkowski, D. J., Stossel, T. P., Orkin, S. H., Mole, J. E., Colten, H. R. and Yin, H. L. Plasma and cytoplasmic gelsolins are encoded by a single gene and contain a duplicated actin-binding domain. Nature 323, 455-458, (1986).

Laine RO, Phaneuf KL, Cunningham CC, Kwiatkowski D, Azuma T, Southwick FS. Gelsolin, a protein that caps the barbed ends and severs actin filaments, enhances the actin-based motility of Listeria monocytogenes in host cells. Infect Immun., 66(8), 3775-3782, (1998).

Lee, WM, Galbraiht, RM. The extracellular actinscavanger system and actin toxicity. N. Engl. J. Med., 326, 1335-1341, (1992).

Leach, A.R. Molecular Modelling. Principles and applications. Longman. London, (1996).

Liepina, I., Czaplewski, C, Janmey P. and Liwo A.. Towards gelsolin amyloid formation. Biopolymers, 76(6), 543-548 (2004).

Maury CP, Sletten K, Totty N, Kangas H, Liljestrom M. Identification of the circulating amyloid precursor and other gelsolin metabolites in patients with G654A mutation in the gelsolin gene (Finnish familial amyloidosis): pathogenetic and diagnostic implications. Lab. Invest, 77, 299304, (1997).

Maury CP, Nurmiaho-Lassila EL, Rossi H. Amyloid fibril formation in gelsolin-derived amyloidosis. Definition of the amyloidogenic region and evidence of accelerated amyloid formation of mutant Asn-187 and Tyr-187 gelsolin peptides. Lab. Invest, 70, 558-564, (1994).

Maury,C.P.J., K. Alli and M. Baumann. Finnish hereditary amyloidosis is caused by a single nucleotide substitution in the gelsolin gene FEBS Lett., 260, 85-87, (1990).

McLaughlin PJ, Gooch J. Crystallization of human gelsolin. FEBS Lett., 302(3), 253-5, (1992).

Meldolesi, J, Pozzan, T.. The endoplasmic reticulum $\mathrm{Ca}^{2+}$ store: a view from the lumen, Trends Biochem Sci., 23(1),10-14, Review, (1998).

Patkowski,A., Seils, J. Hinssen, H, Dorfmuller, T. Biopolymers, 20, 427-435, (1990).
Robinson, R.C., Mejillano, M., Le, V.P., Burtnick, L.D., Yin, H.L., Choe, S. Domain Movement in Gelsolin: A Calcium -Activated Switch. Science, 286, 1939-1942, (1999).

Sun, H.Q., Yamamoto, M., Mejillano, M., Yin, H.L. Gelsolin, a Multifunctional Actin Regultory Protein, Journal of Biological Chemistry, 274, N47, 33179-33182, (1999).

Vasconcellos CA, Allen, PJ, Wohl, ME, Drazen, JM, Janmey PA, Stossel P. Reduction in viscosity of cystic fibrosis sputum in vitro by gelsolin. Science, 263, 969-971, (1994).

Weeds A, Maciver, S., F-actin-capping proteins. Curr. Opin. Cell Biol., 5, 63-39, (1993).

Wen, D., Corina, K., Chow, E., Miller, S., Janmey, P., Pepinsky, R. The plasma and cytoplasmic forms of human gelsolin differ in disulfide structure. Biochemistry, 35, 9700 9709, (1996).

Zapun A, Grammatyka S, Deral G, Vernet T. Calciumdependent conformational stability of modules 1 and 2 of human gelsolin. Biochem J., 350, 873$881,(2000)$.

\section{AUTHOR BIOGRAPHIES}

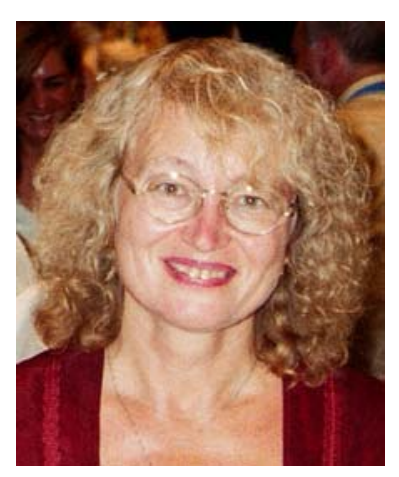

Inta Liepina was born in Riga, Latvia and went to the Latvian University, where she studied physics and obtained her Master of Science degree in physics. Inta Liepina has worked as a visiting scientist in Friedrich Schiller University of Jena, Germany and in the University of Gdansk, Poland. In 2003 she obtained $\mathrm{PhD}$ in theoretical chemistry in the University of Gdansk, Poland. Now Inta Liepina is a researcher at the Latvian Institute of Organic Synthesis, the head of Molecular Biophysics Group. She had calculated conformations of peptides, proteins, lipids, heterocycles and she is interested in molecular modelling of complex systems and protein-ligand, peptide-lipid, protein-protein interactions. inta@osi.lv

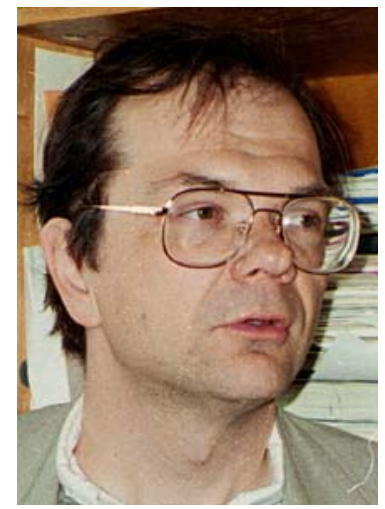

Paul A. Janmey got his A.B. in Chemistry and Philosophy at the Oberlin College in 1976 and Ph.D. in Physical Chemistry at the University of Wisconsin-Madison in 1982 . He worked as an associate professor at the Harvard Medical 
School and as a biologist at the Brigham and Women's Hospital from 1985-1999. As a visiting scientist he was at the University of California, Berkeley, as the lecture he was in the Massachusetts Institute of Technology. Now he is a Professor of Physiology at the University of Pennsylvania, Philadelphia, USA and he is the head of Biophysical Lab, dealing on problems of cytoskeleton.

janmey@mail.med.upenn.edu

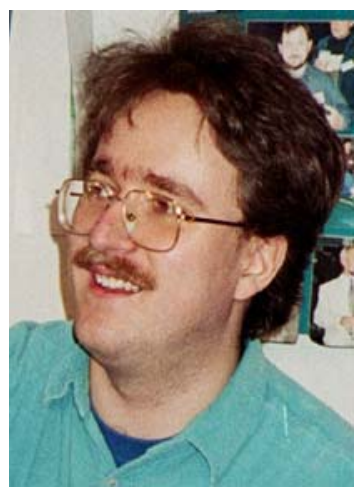

Cezary Czaplewski was born in Gdansk and got his Master of Science degree in the Faculty of Chemistry, University of Gdansk in 1995 and $\mathrm{PhD}$ in theoretical chemistry in 1998. After he went for a couple of years to the USA, Cornell University, where he joined Prof. Harold Scheraga's group. Now he is as an Assistant Professor at the Faculty of Chemistry, University of Gdansk, and his present topic are hydrophobic interactions in protein folding. czarek@chemik.chem.univ.gda.pl

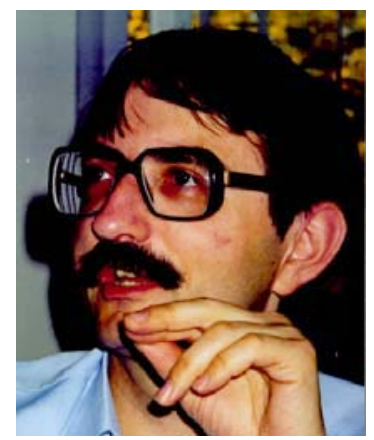

Adam Liwo was born in Gdansk and got his Master of Science degree as well as $\mathrm{PhD}$ theoretical chemistry in the Faculty of Chemistry, University of Gdansk. After he went for a couple of years to the USA, Cornell University, where he joined Prof. Harold Scheraga's group. Now he is a Professor at the Faculty of Chemistry, University of Gdansk, the head of the Molecular Modeling Laboratory, and for the couple of years he is working as visiting scientist in Cornell University again where he is working of protein folding. adam@chemik.chem.univ.gda.pl

\section{ACKNOWLEDGMENTS}

This work was supported by NATO Collaborative Linkage Grant LST.CLG.976647, by Fogarty Foundation grant TW006954, by Latvian Science Council Grant 05.1768, by Gdansk Academic Computer Center TASK and by Warsaw ICM Computer Center. 